\title{
ANTHER NUMBER, ANTHER APICAL APPENDAGES, AND POLLINATION BIOLOGY OF CALYPTOCARPUS VIALIS LESSING (HELIANTHEAE: ASTERACEAE)
}

\author{
James R. Estes \\ Robert Bebb Herbarium \\ University of Oklahoma \\ Norman, OK 76354 \\ University of Nebraska State Museum \\ Lincoln, NE 68588
}

\begin{abstract}
Keywords: secondary pollen presentation, pollen-dome, reproductive system, bordered patch butterflies, invasive species
\end{abstract}

\begin{abstract}
The numbers of disk floret anthers of Calyptocarpus vialis in Wichita County, Texas form a consecutive series of one to four; four anthers $(71 \%)$ and three anthers $(27 \%)$ were most common. Three anthers is an unusual, perhaps singular, number for Asteraceae. These florets also have four-lobed corollas. The extruded pollen-mass is enclosed by a vaulted dome created by apical appendages of the anthers that are lanceolate and inflexed. Pollination appears to be via autogamy (sensu stricto) for disk florets and (considering each head as a single blossom) facultative autogamy and allogamy (both geitonogamy and xenogamy) for the ray florets.

\section{INTRODUCTION}

Calyptocarpus vialis Lessing (straggler daisy, horseherb, or horse herb) is native to eastern Mexico and perhaps as far north as Bexar and Medina, or even Travis, counties in Texas (Nesom 2011). It has spread eastward and become established in all the Gulf Coast states (Strother 2006; Nesom 2011), and Nesom recorded its presence in the Desert Southwest, Arkansas, South Carolina, Illinois, and western Mexico. He also clearly documented the species' recent migration north to the Red River where it was collected in Grayson County. The species has since been reported in Oklahoma (Singhurst et al. 2012; Ryburn et al. 2018), and it may be more widespread in the state. Migration may be partly attributable to the use of straggler daisy in the landscape-trade as a shade-loving groundcover and/or climate change.

Collections of the species from Texas are geographically spotty except in the south and south-central counties; however, it appears to be exceedingly under-collected throughout the state. In the Rolling Plains, the species is known from Tom Green (Nesom 2011), Wichita (this report), and Taylor (Anna Saghatelyn, pers. comm., 19 October 2018) counties. Based on Nesom's map (2011), straggler daisy occurs in all the vegetation areas of Texas (Correll and Johnston 1970) except the High Plains and the far western reaches of the Trans-Pecos Mountains and Basins (Nesom 2011).

Straggler daisy is now one of the most abundant, invasive lawn plants in Wichita County, Texas, especially, but not exclusively, in shady locations. In deep shade under Shumard oak (Quercus shumardii Buckley), two live oak species (Quercus fusiformis Small; Quercus virginiana Mill.), and American elm (Ulmus americana L.), its
\end{abstract}


measure of cover is often close to $100 \%$. It is less dense, but still abundant, in the shade of sycamore (Platanus occidentalis L.), sugarberry (Celtis laevigata Willd.), and western soapberry (Sapindus saponaria L. var. drummondii (Hook \&Arn.) L.D. Benson).

\section{ANTHER NUMBER AND FLORAL MORPHOLOGY IN CALYPTOCARPUS VIALIS}

Five is, by far, the most common anther number among genera in the Asteraceae, although some taxa have only four (Barkley et al. 2006). Disk florets from specimens of Calyptocarpus in Mexico were reported to have either four or five anthers (McVaugh and Smith 1967; McVaugh 1984), and Gibson (2013+) observed both these numbers in Williamson County, Texas. Although the anther number was not listed by the authors in the Illustrated Flora of North Central Texas (Diggs et al. 1999), the illustration by Linny Heagy in the text displayed four anthers.

During a public event at River Bend Nature Center in Wichita Falls in 2014, I used heads of $C$. vialis in an exhibit to demonstrate magnification of plant parts using a Zeiss stereo-microscope-the small heads (diameter 6-9 $\mathrm{mm}$ : apex to apex of opposing rays) of straggler daisy were examined (along with its leaves) with the naked eye, a hand lens, and then the microscope at various powers of magnification. Elementary-aged students observed previously dissected heads and verbally described them, including the unusual achenes and the ray and disk florets. All the heads were taken from plants growing in soil within the Ruby N. Priddy Conservatory. The disk florets that the students examined had only three anthers per floret. These plants had been introduced from a local native plant nursery, perhaps from a single ramet.

To determine if this unexpected number of anthers was a singular horticultural sport, in 2014, I surveyed fresh heads from a number of local populations in northern Wichita County and from specimens collected from the same areas in the Bebb Herbarium (OKL). Anther numbers formed a consecutive series from one to four, but not five.

To determine the proportion of each anther number in early fall of 2018, a $0.5 \mathrm{~km}$ transect along Park Street, Burkburnett, Texas was sampled. The species was personally known to be especially abundant along this street. Flowering heads of $C$. vialis were collected from populations growing along the verge of the street (utility easement of the lot) of every other street address, beginning with an exceptionally large population at 412 Park, east along the south side of the street, and then the alternate addresses on the north side of the street. If five distinct colonies were present, then one open head was taken from each colony. If a single continuous population was encountered, five heads were taken at five-step intervals. If fewer than five distinct colonies were present, then one head was taken from each available colony, with fewer than five collected for that site. If a site lacked Calyptocarpus, the sampling method was maintained, and no counts were made for that "plot." Side streets were not counted as lots. Both mown and non-mown plants were sampled, as were plants in shady and sunny sites. The heads were dissected fresh, and the anther-numbers were determined. If anther number could not be determined from a plant (i.e., a head had completed its flowering phase), then it was discarded and not replaced, unless another head was present on the sampled stem. When an anther number of fewer than four was recorded, a second count from another floret in the sampled head was made to confirm the count. All those counts were confirmed. In sum, 63 heads included florets whose anthers could be tallied.

Sampled specimens along the transect revealed disk florets with two, three, or four 
anthers, with four $(71.43 \%)$ and three $(26.98 \%)$ being the most common numbers (Table 1). I have been unable to find reports of composite genera with three anthers per disk floret in Flora of North America (Barkley et al. 2006).

Even though an earlier collection revealed one head with one anther per disk floret, no one-anthered heads were collected in this sample, and only one head (1.59\%) had two anthers. The two anthers of this head were not fused and were opposite one another; whereas, the anthers were fused in those florets with three and four anthers. It seems likely that the one- and two-anthered florets are developmental anomalies rather than regular occurrences.

All of the heads that were in anthesis from five discrete plants were examined to determine if the number of anthers varied within plants. The number of anthers varied (three versus four) among the plants, but the numbers of anthers among all the disk florets of single heads and all the heads on a single plant were identical with respect to anther number, implying genetic control, but the sample size was small.

The range of anther numbers per disk floret obviously differs between populations in Mexico and central Texas and those in this study from Wichita County. It is unknown whether anther number decreases along the SE to NW distributional axis for C. vialis, or if lower anther numbers occur (but have not been recorded) throughout the species in Texas and Mexico, or if the plants in Wichita County differ in the range of anther numbers from other populations in the state. Because these counts were obtained in late October and early November, perhaps some plants produce fewer anthers in the autumn.

All of the disk florets sampled in Wichita County had four corolla lobes; whereas, the populations sampled by McVaugh and Smith (1964) and McVaugh (1984) in Mexico and Gibson (2013+) in Texas were four- and less commonly fivelobed. In their description of C. vialis, Correll and Johnston (1970) reported five lobes for the corollas of disk florets. Therefore, I conclude that the number of corolla lobes also decreases from south to north.

The adaxial surfaces of the corolla lobes of the Wichita County plants are highly and densely ornamented with turgid papillae; these protuberances are yellow. The papillae are restricted to the adaxial surfaces; they are difficult to discern in herbarium specimens, and they were not discussed in any descriptions of the genus with which I am familiar.

Table 1 Distribution of anther numbers from samples of Calyptocarpus vialis from a transect in Wichita County, Texas. Five flowering heads were sampled from the street verge of each sampled address on Park Street in the city of Burkburnett. The survey was completed from late October to early November.

anther number
5
4
3
2
1
0

individuals
0
45
17
1
0
0


The number and form of ray florets, however, differed among and within the heads of single plants: Numbers of ray florets per head ranged from two to nine. Apices of the rays in this survey were either acute or broadly obtuse, and the number of teeth ranged from zero to five (the latter number on only one ray among five rays from one head on one plant). The teeth on a single ray often varied in size. This is in contrast to Correll and Johnston's (1970) description, which indicated that the rays are "equally 5-toothed." Gibson's (2013+) account indicated that most rays were two to three lobed (perhaps equivalent to teeth in this account and in Correll and Johnston's description) with a few, apparently, entire (in Gibson's description, "unlobed" was included in parentheses). In addition, with the exception of one head, the apices of the rays observed in this study were more appropriately referable to "teeth" rather than "lobes." It is possible that the numbers of teeth per ray diminish from south to north, but additional analysis would be necessary to determine if that is the case.

\section{ROLE OF APICAL APPENDAGES OF CALYPTOCARPUS VIALIS ANTHERS}

The anthers of the disk florets of $C$. vialis dehisce introrsely, and sweeping hairs on the distal surface of the style extrude the pollen-mass upward and out of the anther tube as per Proctor and Yeo's (1972), Yeo's (1993), and Carlquist's (1976) general descriptions for some genera in the family. However, rather than being presented in an open-cup formed from the appendages as described by Carlquist, in this species the inflexed appendages combine to form a closed, dome- or cap-like covering (hereinafter in this account referred to as a "pollen-vault" or "vault") over the pollenmass. The entire pollen crop from the anthers was swept into the vault, rather than incrementally (Proctor and Yeo 1972). Small (1915) recorded other composite genera with appendages that are inflexed. However, I did not locate any descriptions that implied a pollen-holding function for any other genera of the family.

The pollen-vault is formed as a result of the lanceolate appendages being curved inward (rather than outward) and fitting together closely. Therefore, the pollen is not immediately and readily available to foragers or for deposition on the stigmas of the ray florets. It was not visually apparent to this viewer, whether the margins of the appendages coalesced or cohered or were just closely fitted. However, judging by how readily they separated during dissection, I concluded that they were merely closefitting (immature appendages were observed to be distinct). The yellow pollen, therefore, might be accessible to insects at the seams of the vault. In the heads with only two anthers, the pollen was only partially covered. That might result in the more ready deposition of pollen on styles of ray florets.

\section{POLLINATION BIOLOGY OF CALYPTOCARPUS VIALIS IN NORTHWEST TEXAS}

A sod of C. vialis was isolated in a Plexiglas-covered indoor terrarium to monitor achene-set in the absence of potential pollinators and to observe floral behavior. All heads that were already open and flowering or fruiting were excised. Newly-opening heads $(n=10)$ were observed daily for one week. The plants in the sod failed to thrive indoors, and nine of the ten heads opened but shriveled within three weeks, and of the nine, six were both shriveled and brown. None of the nine exhibited fully developed achenes, though melanin did form in many of the flat, unfilled ovaries (three-week duration). Only one head formed achenes that appeared mature (expanded in all three dimensions, 
dark brown). All of the achenes that appeared normal were from ray florets. None of the disk florets from that head produced mature achenes. I do not believe any conclusions regarding pollination can be drawn from this experiment.

Based on observations of capitulum development in the field and the terrariumgrown plants, when the flower buds open, on the first day of anthesis, the pistillate ray florets of blossoms of $C$. vialis emerge first from the buds, often in the late afternoon, but also other times throughout the day. This is equivalent to protogyny (Faegri and Pijl 1966; Proctor and Yeo 1972), presumably favoring cross-pollination. In all examined Calyptocarpus, the styles of this whorl of florets are oriented more or less radially, even though the flattened achenes are tangentially oriented. Pollen-carrying floral visitors could deposit pollen on these stigmas at any time after opening. I was unable to determine directly if nectar was being produced by the ray florets.

The outermost whorl of disk florets opens throughout the second- or third-day of anthesis; however, the pollen is not exposed until later in the same day. The centrally-positioned limb of the ray florets' styles is, at this time, in close proximity to or even in contact with the pollen-vaults of the disk florets. However, the vault's closure clearly restricts pollen transfer, thereby effectively extending the period of protogyny. In the field, many of the ray stigmas appear devoid of pollen, but a few have scattered grains and in a few older heads, the tips of the styles of ray florets exhibited a mass of pollen.

The anthers of the disk florets ultimately grow and project through the pollen-mass and from the vault. In some heads, the styles emerge from the apex of the vault, and in others, one style branch breaks through one lateral suture and the other through an opposite suture. In the latter instance, the styles were pollen-coated; in those that emerged from the apex, some bore pollen along the stigmatic lines, but others seemed to be pollen-free. Clearly the tubular disk florets of $C$. vialis exhibit a delayed secondary pollen presentation (cf. Small 1915; Yeo 1993; Leins and Erbar 2006). However, many (probably most) of the emergent stigmas are already selfpollinated, and all those stigmas that emerged laterally are covered with selfpollen. Within a capitulum, pollination of the ray florets of the head could also occur at this time.

During the study period (late summer and autumn) in North Texas, the heads were visited by dipterans, mostly syrphid flies, throughout the day and by small lepidopterans from about 1100 hours until 1800 hours. The visitors were not collected, and it is unknown if any carry C. vialis pollen. [The author is aware of J. W. McSwain's retort that not all flower visitors are pollinators (Robbin Thorp, pers. comm.; Otto Solbrig, pers. comm.).] The lepidopterans probed the florets, as though they were foraging for nectar, which is the only evidence of nectar production in these populations. Parsons (2018) reported that straggler daisy is a host for caterpillars of bordered patch butterflies (Chlosyne lacinia), but none were observed in Wichita Country. Small butterflies were cited as anthophilous visitors at the Lady Bird Wildflower Center in Austin (2018); that listing did not mention syrphids. Straggler daisy was introduced into Wichita County and to potential pollinators that may differ from those available in Mexico and southern Texas and earlier in the season in North Texas.

The pollination system of C. vialis appears to be facultative autogamousallogamous facilitated by the described secondary pollen presentation. This inference could be tested in insect exclusion- and artificial pollination-studies. The pollen-vault assures that the disk florets have the potential for self-pollination, all the while preventing immediate pollination of 
ray florets by the pollen of disk florets from the same blossoms. Thus, the more numerous disk florets appear to be primarily autogamous. The pistillate ray florets acquire pollen from disk flowers in the same head (autogamous) [It is often useful in terms of pollination and reproductive systems to consider the composite head as a single "blossom" (sensu Faegri and Pijl, 1966; Proctor and Yeo, 1972).], different heads on the same plant (geitonogamous), or heads from a different plant (xenogamous). A facultative reproductive system such as this could be advantageous for an invasive species that spreads into a new area with a different set of pollinators. However, pollination of straggler daisy appears to rely on available indigenous insects rather than a few specialized anthophilous insects. This dual pollination system may be useful in mat-forming species such as this with many heads of the same genotype in close proximity (Estes and Brown 1973). Geitonogamy must be commonplace in this species. In field observations, all of the fruiting heads studied bore a full array of the cuneate-shaped, two-spined achenes.

\section{CONCLUSIONS}

The floral morphology of the northwestern Texas populations of Calyptocarpus vialis is distinctive from those reported from south-central Texas and Mexico with regard to the numbers of anthers (from four and five in the south to three to four in Wichita County) and the numbers of corolla lobes of disk florets (from four and five in the south to four in Wichita County). The highly ornamented faces of the corolla lobes have not been previously described in any floras or generic descriptions of this species seen by this author.

Although definitive breeding studies were not accomplished, it appears that the species is largely self-pollinated. It is unclear if the northerly migration and presumed self-fertilization are correlated with the decreasing anther number; reduction of pollen production with decreasing anther number would be compatible with those features. Pollen retention by the pollen-vault produced by the apical anther appendages also appears to favor self-pollination.

\section{ACKNOWLEDGMENTS AND COLLECTIONS}

Specimens collected by Estes in 2014 are deposited at the Robert Bebb Herbarium (OKL). A count of three-anthers was confirmed by Ronald J. Tyrl for a specimen from the Herbarium. Synantherologists John Strother and Bruce Baldwin at the University of California; Luc Brouillet, Université de Montréal; and Linda Watson, Oklahoma State University, all kindly responded that each was unaware of any composites that regularly produce three anthers per floret.

Dr. Anna Saghatelyn, McMurry University in Abilene, Texas, generously provided her observations and collections of Calyptocarpus vialis. Dr. Richard Kazmaier, West Texas A\&M University, provided an interesting discussion of the abundance of C. vialis in Terrell County, Texas, and he had not noted the plant in the Panhandle, albeit, he had not searched for it.

I am grateful to Assistant Librarian and Interlibrary Loan Director Ms. Ashlee O'Rourke and all the staff of the Burkburnett Public Library for provision of their services and library loans. The Sooner Xpress/Interlibrary Loan provided copies of journal articles on line that were essential to the conduct of this study.

The original anther-counts of three were from a plant grown in a glasshouse at River Bend Nature Center in Wichita Falls, Texas and made in conjunction with a number of young visitors during an open-house event at the Nature Center.

Three anonymous reviewers made several substantive suggestions that greatly 
aided interpretation of this paper, and I am deeply appreciative of their contributions.

\section{LITERATURE CITED}

Barkley, T.M., L. Brouillet, and J.L. Strother. 2006. Asteraceae. In: Editorial Committee, eds. Flora of North America North of Mexico 19:3-16. New York (NY) and Oxford (England): Oxford University Press.

Carlquist, S. 1976. Tribal interrelationships and phylogeny of the Asteraceae. Aliso 8:465-492.

Correll, D.S. and M.C. Johnston. 1970. Manual of the Vascular Plants of Texas. Renner (TX): Texas Research Foundation.

Diggs, G., B. Lipscomb, and R. O'Kennon. 1999. Shinners and Mabler's Illustrated Flora of North Central Texas (Sida, Botanical Miscellany). Fort Worth (TX): Botanical Research Institute of Texas.

Estes, J.R. and L.S. Brown. 1973. Entomophilous, intrafloral pollination in Phyla incisa. American Journal of Botany 60:413-415.

Faegri, K. and L. van der Pijl. 1966. Principles of Pollination Ecology, 3rd revised ed. Oxford (England): Pergamon.

Gibson, A.C. 2013+. Vascular plants of Williamson County. http://w3.biosci.utexas.edu/prc/ (November 2018).

Lady Bird Johnson Wildflower Center. 2018. Calyptocarpus vialis. https://www.wildflower.org/plants/resu lt.php?id plant $=$ cavi2 $($ November 2018).

Leins, P. and C. Erbar. 2006. Secondary pollen presentation syndromes of the Asterales-A phylogenetic perspective. Botanische Jabrbücher für Systematik 127:83103.
McVaugh, R. 1984. Calyptocarpus. In: Anderson, William R., ed. Flora NovoGaliciana: A Descriptive Account of the Vascular Plants of Western Mexico 12:200201. Ann Arbor (MI): University of Michigan Press.

McVaugh, R. and N.J. Smith. 1967. Calyptocarpus vialis and C. wendlandii (Compositae). Brittonia 19:268-272.

Nesom, G. 2011. Is Calyptocarpus (Asteraceae) native or introduced in Texas? Phytoneuron 2011-1:1-7.

Parsons, J., ed. 2018. Horseherb or straggler daisy. PLANTanswers.

http://plantanswers.com/Articles/Hors eherbOrStragglerDaisy.asp (December 2018).

Proctor, M. and P. Yeo. 1972. The Pollination of Flowers. New York (NY): Taplinger.

Ryburn, A.K., S.C. Barber, P. Buck, G.M. Caddell, W.J. Elisens, J.R. Estes, M. Fishbein, P. Folley, L.K. Magrath, A.J. Moore, C.L. Murray, B.A. Smith, C.E.S. Taylor, R.J. Tyrl, R.A. Thompson, J.B. Walker, and L.E. Watson. 2018. Flora of Oklahoma: Keys and Descriptions, 2nd ed. Oklahoma City (OK): Flora Oklahoma Inc.

Singhurst, J.R., J.N. Mink, and W.C. Holmes. 2012. Two vascular plant species new to Oklahoma. Phytoneuron 2012-5:1-2.

Small, J. 1915. The pollen presentation mechanism in the Compositae. Annals of Botany 29(115):457-470.

Strother, J. 2006. Calyptocarpus. In: Flora of North America Editorial Committee, eds. Flora of North America North of Mexico 21: 65-67. New York (NY) and Oxford (England): Oxford University Press.

Yeo, P.F. 1993. Secondary Pollen Presentation: Form, Function, and Evolution. Plant Systematics and Evolution, Supplement 6. Wien (Austria) and New York (NY): Springer-Verlag. 